Article

\title{
Efficacy of Sweet Potato Starch-Based Coating to Improve Quality and Safety of Hen Eggs during Storage
}

\author{
Abdulhakim Sharaf Eddin and Reza Tahergorabi * \\ Food and Nutritional Sciences Program, North Carolina Agricultural and Technical State University, Greensboro, \\ NC 27411, USA; aeddin@bienetrelabs.com \\ * Correspondence: rtahergo@ncat.edu; Tel.: +1-336-285-4865
}

Received: 26 February 2019; Accepted: 18 March 2019; Published: 22 March 2019

check for updates

\begin{abstract}
Egg deterioration occurs during storage time, which leads to quality loss. Thus, different preservations methods have been used to extend the shelf-life and maintain the safety of eggs. Edible coating materials based on biopolymers, such as starches and other renewable sources, have been used for different food products and been identified as an effective method of food preservation. In this study, eggs were coated with edible coatings prepared from sweet potato starch (SPS) and varying levels of thyme essential oil (TEO), including 0 (control), $2 \%, 4 \%$, and $6 \%$. The quality and safety of the coated and uncoated eggs during five weeks of storage at $25^{\circ} \mathrm{C}$ were studied. The application of $4 \%$ TEO in SPS-based coatings maintained the quality and safety of eggs two weeks longer than non-coated eggs. This study showed that the SPS-TEO coating could be useful in extending the shelf life of eggs during storage time, by delaying changes in egg quality.
\end{abstract}

Keywords: sweet potato starch; egg; quality; edible coating; thyme essential oil

\section{Introduction}

Eggs are globally consumed in people's diets, and they are an excellent source of high-quality protein and other nutrients [1]. A large, raw, and fresh egg which weighs 50 g provides $74.5 \mathrm{kcal}$, and contains $6.25 \mathrm{~g}$ proteins and $5.01 \mathrm{~g}$ total fat. According to the literature, eggs are considered to be the main source of cholesterol in the diet. However, more than half of the total fat is unsaturated (1.9 $\mathrm{g}$ monounsaturated, and $0.7 \mathrm{~g}$ polyunsaturated). In addition, eggs are a good source of vitamins and minerals, such as vitamin A, vitamin E, folate, iron, and zinc [2].

The grading of eggs depends on the weight and internal quality of the eggs, such as the egg white, yolk, and air cell. The movement of carbon dioxide and moisture through the shell during the storage of eggs may affect the quality of the eggs, including weight loss and interior quality deterioration, in addition to the microbial contamination commonly known as Salmonella enteritidis. The possible sources of this contamination in eggs are dust, nesting materials, and feces [3], that can penetrate into the interior of eggs or contaminate the surface of the egg shell [1].

The increasing resistance of microorganisms to traditional chemicals and drugs has prompted scientists to search for natural sources of antimicrobials with greater effectiveness against a large variety of organisms, and to maintain the quality of eggs [4]. Recently, there has been increasing interest in the use of natural antimicrobials in food products to maintain food quality and enhance safety and stability. Natural antimicrobials are widely acknowledged as alternatives to synthetic agents. Various natural antimicrobials, like plant essential oils, have been tested. These compounds are effective antimicrobials and have no allergenic potential. Our previous research has shown that thyme essential oil (TEO) has strong antimicrobial activity against species of Salmonella [5]. TEO does 
not impose any risk of allergenicity and has no adverse effects on humans, so it is recognized as safe (GRAS) by the European Commission (EC) and the United States Food and Drug Administration (USFDA) [6]. However, direct application of natural antimicrobials may adversely affect the sensory properties of the foods.

An edible coating - a thin layer of biopolymers—could be a carrier of antimicrobials which extend the shelf life of food. Starch is the predominant form of polysaccharide that is used to manufacture polysaccharide-based edible coatings. Sweet potato starch (SPS) is obtained from sweet potatoes (Ipomoea batatas Lam), and is cost-effective and readily available across the globe. In our previous research, biodegradable films from SPS were developed which possess good mechanical properties [7]. Although SPS films are efficient gas barriers, they have weak moisture permeability because of their hydrophilic properties. Thus, our group [8] tested the incorporation of TEO into SPS-based coating. Our results indicate that this system could be useful in extending the shelf life of shrimp meat during refrigerated storage.

To the best of our knowledge, no literature is available on the effect of a starch and essential oil system in preserving the quality and safety of eggs during storage. Thus, the main goal of this research was to develop SPS-based edible coatings that incorporated TEO (antimicrobial agent) to address issues of the quality and safety of food, as well as environmental sustainability. The specific objectives of this study were to: (a) evaluate the quality (Haugh units, yolk index, shell breaking strength, shell color, albumen $\mathrm{pH}$, and weight loss); and (b) investigate the antibacterial activity of SPS-based edible coatings on eggs during five weeks of storage at $25^{\circ} \mathrm{C}$.

\section{Materials and Methods}

\subsection{Preparation of Egg Samples}

White shell hens' eggs were procured from a grocery store and used in this study. Upon arrival, eggs were screened for defects (cracks, breakage, inconsistent shell color, and cleanliness), then the eggs were weighed for the desirable weight range (50-70 g) using a balance. Eggs were kept in a refrigerator at $4{ }^{\circ} \mathrm{C}$ overnight before coating the next day.

\subsection{Preparation of Coating Solutions}

In order to prepare the edible coating from SPS, an adequate amount of SPS (50 g) was mixed at $25^{\circ} \mathrm{C}$ with $1 \mathrm{~L}$ of distilled water for $20 \mathrm{~min}$. To initiate gelatinization, the temperature of the solution was raised up to $80^{\circ} \mathrm{C}$ and continued for $30 \mathrm{~min}$. Then, glycerol at $2 \%(w / w$, on dry basis of the weight of starch) (Fisher Scientific, Fair Lawn, NJ, USA), was added and mixed for $5 \mathrm{~min}$ [7]. In this study, TEO (Thymus vulgaris, New Direction Aromatics, Mississauga, ON, Canada) at various levels including $0.0 \%, 2.0 \%, 4.0 \%$, and $6.0 \%(\mathrm{v} / \mathrm{v})$ was mixed with Tween 80 (Fisher Scientific, Fair Lawn, NJ, USA) and homogenized in the coating solution for $5 \mathrm{~min}$ using a laboratory homogenizer (Homogenizer, OMNI International, Kenneswa, GA, USA). Finally, ultrasonication was performed to degas the coating solution. This practice prevents any bubble formation in the coating solution.

\subsection{Coating of Eggs with Coating Solutions}

At least $2 \mathrm{~h}$ prior to the coating treatment, the eggs were adjusted to room temperature to prevent any condensation which may interfere with coating. The eggs were washed with clean tap water and dried for $30 \mathrm{~min}$. They were then gently immersed in the coating solutions using sanitized tongs for $1 \mathrm{~min}$. This process was repeated once more, and they were then dried at room temperature for $3 \mathrm{~h}$. The eggs were subsequently placed in plastic egg trays and stored at room temperature (approximately $25^{\circ} \mathrm{C}$ ) for five weeks during the experiments. The eggs were randomly assigned to five treatments, including treatment 1 ( $\mathrm{T} 1=$ uncoated, served as control), treatment 2 (T2 = SPS-based coating), treatment $3(\mathrm{~T} 3=$ SPS-based coating with TEO at $2 \%)$, treatment $4(\mathrm{~T} 4=$ SPS-based coating with TEO at $4 \%$ ), and treatment 5 (T5 = SPS-based coating with TEO at $6 \% w / w$ ). Ten eggs were 
assigned to each treatment group. Among them, six eggs were randomly selected from each group during the storage time for quality and safety analyses.

\subsection{Determination of Haugh Unit}

A tripod micrometer (Model S-6428, B.C. Ames Inc, Melrose, MA, USA) was used to measure the height of the yolk and albumen. The following formula was then used to calculate the Haugh units of eggs:

$$
\mathrm{HU}=100 \log \left(H-1.7 \times W^{0.37}+7.57\right)
$$

where $\mathrm{HU}=$ Haugh Units; $H$ = height of the albumen (mm); and $W=$ egg weight (g) [9].

\subsection{Yolk Index}

Stadelman [10] described the yolk index as the ratio of yolk height to yolk width.

\subsection{Mechanical Properties of the Egg}

Shell breaking strength is defined as the minimum force (kgf) required to cause failure of the shell. Egg shell breaking strength was measured using a stable micro systems texture analyzer (Model TAXT2, Texture Technologies Corp, Scarsdal, NY, USA). Shell thickness was measured after removing the internal membranes of the egg shell [11].

\subsection{Color Properties of the Shell}

Clean and dirt-free eggs with a smooth shell surface were selected for color measurements. A Minolta Chroma Meter CR-400/410 colorimeter (Minolta, Osaka, Japan) was used to determine the color properties of coated and uncoated egg shells. The values of the CIE (Commission Internationale d'Eclairage of France) color method using tristimulus color values were determined.

\subsection{Albumen $\mathrm{pH}$ Measurement}

Ten $\mathrm{mL}$ of thin and thick albumens were mixed inside centrifuge tubes and homogenized for $20 \mathrm{sec}$ using a laboratory homogenizer (Homogenizer, OMNI International, Kenneswa, GA, USA), then the $\mathrm{pH}$ of the albumen was measured using a $\mathrm{pH}$ meter (accumet $\mathrm{AB}$ 150, Fisher Scientific, Fair Lawn, NJ, USA).

\subsection{Determination of Weight Loss}

Eggs were individually weighed in the semi-analytical balance with an accuracy of $0.01 \mathrm{~g}$ (BL3200H, Shimadzu, Tokyo, Japan) for the determination of the average egg weight. The weight loss of the coated whole eggs during storage was expressed in a percentage and calculated as following:

$$
\text { weight loss }(\%)=\frac{\text { initial weight of whole coated egg at day } 0(\mathrm{~g}) \text {-weight of whole eggafter storage }(\mathrm{g})}{\text { initial weight of whole coated egg at day } 0(\mathrm{~g})} \times 100
$$

\subsection{Inoculation on Egg Shell}

Eggs were sanitized with $70 \%$ ethanol using a spray method and kept in a biosafety cabinet until completely dry. A spot inoculation method described by Jindal and Sritham [12] was used in this study, with some modification. Colonies of Salmonella enterica (ATCC 53648) were isolated from Trypticase soy broth (TSB) agar plates and transferred into tubes containing TSB broth. The incubated TSB broth, which was supplemented with $0.6 \%$ yeast extract (TSBYE) (Difco, Becton Dickinson Co., Durham, NC, USA), gave cell populations of approximately $10^{8} \mathrm{CFU} / \mathrm{mL}$. Then, the cultures were serially diluted with sterile peptone water $(0.1 \%, v / v)$ to approximately $10^{7} \mathrm{CFU} / \mathrm{mL}$. One hundred microliter of bacteria was spot inoculated onto the marked surface area $\left(1.5 \mathrm{~cm}^{2}\right)$ on the egg shells. Uncoated eggs served as control samples. The inoculum was applied in approximately equal volumes 
in eight-ten spots over the marked surfaces. Eggs samples were air dried for $1 \mathrm{~h}$ under the biosafety cabinet to allow the attachment.

\subsection{Antibacterial Analysis}

Dried droplets were swabbed using sterile and moist cotton buds, and dispersed into $9 \mathrm{~mL}$ of sterilized peptone solution $(0.1 \%, w / v)$ and vortexed vigorously for $\sim 1 \mathrm{~min}$. Then, $1 \mathrm{~mL}$ of peptone solution was withdrawn and serially diluted into $9 \mathrm{~mL}$ of peptone water. One hundred microliters of appropriate dilutions were surface plated onto brain heart infusion (BHI). Plates were incubated at $37^{\circ} \mathrm{C}$ for $24 \mathrm{~h}$, and colonies of Salmonella were counted and reported as colony forming units (CFU).

\subsection{Statistical Analysis}

The experiments were independently triplicated $(n=3)$. Two-way analysis of variance (ANOVA) was applied to the data at a probability level of 0.05 . Tukey's test was used to determine the significant difference between treatments. The statistical software of SAS (version 16.0, SAS Institute, Cary, NC, USA) was utilized to analyze all the statistical analyses of data.

\section{Results and Discussion}

\subsection{Haugh Unit}

Table 1 represents the Haugh unit of uncoated and coated eggs during five weeks of storage at $25^{\circ} \mathrm{C}$. The Haugh unit is used to determine the internal quality (quality of albumen) of table eggs. It is estimated from the height of the egg albumen as a distance of $1 \mathrm{~cm}$ from the edge of egg yolk. The height of the albumen is used to assess its viscosity. Albumens with lower viscosity are rated as poor quality due to a low concentration of proteins [13]. In this research, Haugh units reduced significantly $(p<0.05)$ for all treatments during storage time, but the reduction in Haugh unit was more pronounced for uncoated samples. Mota, Abreu, Pereira, Freitas, Silva, and Lima [14] reported similar results for eggs that were coated with yam starch and stored for 28 days at $25{ }^{\circ} \mathrm{C}$. They concluded that the albumen becomes less viscous with storage and consequently the albumen height reduces, resulting in lower Haugh units values. However, there was no significant $(p>0.05)$ difference for eggs that were coated with SPS-based coating incorporated with $4 \%$ and $6 \%$ TEO, except for week 3.

Table 1. Haugh unit of non-coated and coated eggs during five weeks of storage at $25^{\circ} \mathrm{C}$.

\begin{tabular}{cccc}
\hline Treatments & 1 Week & 3 Weeks & 5 Weeks \\
\hline T1 & $83.71 \pm 0.87^{\mathrm{ef}}(\mathrm{AA})$ & $72.98 \pm 0.96^{\mathrm{i}}(\mathrm{AA})$ & $62.31 \pm 1.84^{\mathrm{j}}(\mathrm{A})$ \\
T2 & $93.51 \pm 2.48^{\mathrm{bc}}(\mathrm{AA})$ & $76.35 \pm 1.1^{\mathrm{igh}}(\mathrm{AA})$ & $72.1 \pm 0.9^{\mathrm{j}}(\mathrm{AA})$ \\
T3 & $87.52 \pm 0.89^{\mathrm{de}}(\mathrm{AA})$ & $80.97 \pm 3.39^{\mathrm{fg}}(\mathrm{AA})$ & $73.1 \pm 0.88^{\mathrm{i}}(\mathrm{AA})$ \\
T4 & $97.28 \pm 1.58^{\mathrm{ab}}$ (AA) & $80.04 \pm 1.38^{\mathrm{fgh}}(\mathrm{AA})$ & $75.89 \pm 1.66^{\mathrm{hi}}(\mathrm{AA})$ \\
T5 & $98.37 \pm 0.35^{\mathrm{a}}(\mathrm{AA})$ & $91.26 \pm 0.92^{\mathrm{cd}}(\mathrm{AA})$ & $76.81 \pm 1.79^{\mathrm{igh}}(\mathrm{AA})$ \\
\hline
\end{tabular}

Data are given as mean values \pm standard deviation. Different letters within the same row indicate significant differences (Tukey's Test, $p<0.05$ ) between mean values.

According to Yüceer and Caner [15], the eggs can be graded as: AA, HU > 72; A, HU = 71-60; $\mathrm{B}, \mathrm{HU}=59-31$; and $\mathrm{C}, \mathrm{HU}<30$. Therefore, in our study all coated eggs maintained an AA grade throughout the storage period, but uncoated eggs dropped from grade AA to grade A at the end of storage. Yüceer and Caner [15], who used lysozyme-chitosan coatings, reported that the Haugh unit decreased after six weeks of storage for uncoated eggs; on the other hand, lysozyme and chitosan maintained the albumen quality after the storage period. The findings of our study demonstrated that SPS in combination with TEO was able to preserve the albumen quality during long-term storage. 


\subsection{Yolk Index}

The internal quality of table eggs is also estimated from their yolk index. Table 2 reflects the yolk index for coated and uncoated eggs. The ratio of yolk height to yolk width is considered to be the yolk index. It is an indirect measure of the strength of the yolk vitelline membrane and can be used to assess egg freshness-the higher the yolk index, the better the yolk quality [16]. The present study showed that the yolk index of eggs that were coated with the SPS-based coating with incorporated TEO was not significantly higher $(p>0.05)$ than eggs that were uncoated after five weeks of storage at $25^{\circ} \mathrm{C}$. Similarly, Obanu and Mpieri [17] showed that there were no significant $(p>0.05)$ differences in the yolk index values of eggs coated with cottonseed, coconut, and groundnut oils after 36 days of storage at room temperature. However, in our study, the yolk index values for coated eggs ( 0.2 to 0.28$)$ were numerically higher than uncoated (0.22) eggs after five weeks of storage. A decrease in yolk index indicates a weakening of the yolk vitelline membrane which separates the yolk from the albumen, which results in the exchange of gas and water between the albumen and yolk [18]. The Haugh unit, weight loss, and yolk index are highly correlated. This study showed that an SPS-based coating and TEO could preserve the albumen and yolk quality of eggs for at least three more weeks compared to those of uncoated eggs, since the coating reduces the rate of moisture and $\mathrm{CO}_{2}$ loss from the albumen via the eggshell.

Table 2. Yolk index of non-coated and coated eggs during five weeks of storage at $25^{\circ} \mathrm{C}$.

\begin{tabular}{cccc}
\hline Treatments & $\mathbf{1}$ Week & 3 Weeks & $\mathbf{5}$ Weeks \\
\hline T1 & $0.33 \pm 0.01^{\text {bcd }}$ & $0.24 \pm 0.02^{\text {ghi }}$ & $0.22 \pm 0.01^{\text {ghi }}$ \\
T2 & $0.34 \pm 0.02^{\mathrm{abc}}$ & $0.26 \pm 0.02^{\text {efgh }}$ & $0.21 \pm 0.01^{\text {hi }}$ \\
T3 & $0.36 \pm 0.04^{\mathrm{abc}}$ & $0.26 \pm 0.01^{\text {efgh }}$ & $0.2 \pm 0.02^{\mathrm{i}}$ \\
T4 & $0.38 \pm 0.01^{\mathrm{ab}}$ & $0.3 \pm 0.02^{\text {cdef }}$ & $0.25 \pm 0.02^{\text {fghi }}$ \\
T5 & $0.4 \pm 0.02^{\mathrm{a}}$ & $0.32 \pm 0.01^{\text {cde }}$ & $0.28 \pm 0.03^{\text {defg }}$ \\
\hline
\end{tabular}

Data are given as mean values \pm standard deviation. Different letters within the same row indicate significant differences (Tukey's Test, $p<0.05$ ) between mean values.

\subsection{Shell Breaking Strength}

The external quality of table eggs is assessed from its shell strength. Egg shell strength is very important since it reduces the susceptibility of egg shell breakage due to storage and handling. Shell breaking strength is defined as the minimum force, in Newton, that is required to cause failure of the shell [19]. Table 3 represents the shell breaking strength for both coated and uncoated eggs.

Table 3. Shell breaking strength of non-coated and coated eggs during five weeks of storage at $25^{\circ} \mathrm{C}$.

\begin{tabular}{cccc}
\hline Treatments & 1 Week & 3 weeks & 5 Weeks \\
\hline T1 & $4.59 \pm 0.1^{\mathrm{g}}$ & $4.07 \pm 0.01^{\mathrm{h}}$ & $3.76 \pm 0.06^{\mathrm{i}}$ \\
T2 & $5.47 \pm 0.04^{\mathrm{d}}$ & $4.87 \pm 0.05^{\mathrm{f}}$ & $4.74 \pm 0.06^{\mathrm{fg}}$ \\
T3 & $5.89 \pm 0.09^{\mathrm{b}}$ & $5.75 \pm 0.08^{\mathrm{bc}}$ & $5.63 \pm 0.07^{\mathrm{cd}}$ \\
T4 & $6.27 \pm 0.02^{\mathrm{a}}$ & $5.54 \pm 0.16^{\mathrm{cd}}$ & $5.44 \pm 0.11^{\mathrm{d}}$ \\
T5 & $6.28 \pm 0.1^{\mathrm{a}}$ & $5.61 \pm 0.1^{\mathrm{cd}}$ & $5.18 \pm 0.05^{\mathrm{e}}$ \\
\hline
\end{tabular}

Data are given as mean values \pm standard deviation. Different letters within the same row indicate significant differences (Tukey's Test, $p<0.05$ ) between mean values.

The present study reflected that SPS-based coatings incorporated with different concentrations of TEO significantly improved the shell strength of table eggs compared to their counterparts that were either uncoated or coated with only SPS. The findings of the present study complemented the findings of Zhao et al. [20] and Wardy et al. [21]. Wardy et al. [21] highlighted that a polysaccharide-based coating could ensure the AA gradation of table eggs, even after prolonged storage. Table eggs are graded based on different parameters and shell strength is one of the significant markers that 
determines the grade of table eggs. Hence, the present study indicated that SPS-based coatings incorporated with different concentrations of TEO were effective in retaining the quality of table eggs under different storage conditions. On the other hand, Zhao et al. [20] highlighted the importance of shell strength in reducing the bacterial content of table eggs. This study clearly indicates the potential application of the SPS-based coating in minimizing egg breakage, especially when TEO is used.

\subsection{Color Parameters}

The other external parameter that is used to express the external quality of table eggs is color parameters. Egg shell color affects the consumer acceptance of eggs. The color of the shell of commercial table eggs is brown, white, or tinted. Odabaşi et al. [22] highlighted that the color of an egg diminishes with its age or time of storage. The color parameters of coated and uncoated eggs are presented in Table 4. The tristimulus color values were used to assess the color properties of coated and uncoated eggs. By convention the $L^{*}$ value ranged from 0 (black shade) to 100 (white shade), while the $a^{*}$ value ranged from +60 (red) to -60 value (green). On the other hand, the positive values of the $b^{*}$ value indicated a yellow shade, while the negative values of the $b^{*}$ value indicated a blue shade. The present study reflected that SPS-based coatings incorporated with different concentrations of TEO were effective in preserving the color of egg shells. The addition of TEO at different concentrations of $2 \%, 4 \%$, and $6 \%$ reduced the $L^{*}$ value of egg shells, due to the indigenous pigments of TEO. Although the $L^{*}$ values of coated eggs decreased, these values ranged from 95.92 to 94.29 , indicating light-colored coated eggs after five weeks of storage.

Table 4. Color values $\left(L^{*}, a^{*}, b^{*}\right)$ of non-coated and coated eggs shell during five weeks of storage at $25^{\circ} \mathrm{C}$.

\begin{tabular}{|c|c|c|c|}
\hline Treatments & 1 Week & 3 Weeks & 5 Weeks \\
\hline \multicolumn{4}{|c|}{$L^{*}$} \\
\hline $\mathrm{T} 1$ & $96.63 \pm 0.39^{\mathrm{ab}}$ & $96.42 \pm 0.88^{\mathrm{ab}}$ & $95.92 \pm 0.63^{\mathrm{abc}}$ \\
\hline $\mathrm{T} 2$ & $96.11 \pm 0.73^{\mathrm{abc}}$ & $96.99 \pm 0.52^{\mathrm{a}}$ & $96.87 \pm 0.09^{\mathrm{a}}$ \\
\hline $\mathrm{T} 3$ & $92.23 \pm 1.43^{g h}$ & $93.68 \pm 0.23^{\mathrm{efg}}$ & $94.38 \pm 0.37^{\text {cde }}$ \\
\hline $\mathrm{T} 4$ & $93.95 \pm 0.26^{\text {defg }}$ & $93.74 \pm 0.60^{\mathrm{efg}}$ & $94.36 \pm 0.68^{\text {cde }}$ \\
\hline $\mathrm{T} 5$ & $91.69 \pm 0.25^{\mathrm{h}}$ & $94.37 \pm 0.54^{\text {cde }}$ & $94.29 \pm 0.41^{\text {cdef }}$ \\
\hline \multicolumn{4}{|c|}{$a^{*}$} \\
\hline $\mathrm{T} 1$ & $-0.38 \pm 0.02^{\text {bcde }}$ & $-0.16 \pm 0.07^{a b c}$ & $-0.59 \pm 0.07^{\mathrm{def}}$ \\
\hline $\mathrm{T} 2$ & $-0.50 \pm 0.08^{\mathrm{cdef}}$ & $-0.02 \pm 0.06^{\mathrm{ab}}$ & $0.48 \pm 0.10^{\text {cdef }}$ \\
\hline $\mathrm{T} 3$ & $-0.21 \pm 0.12^{\mathrm{abcd}}$ & $-0.09 \pm 0.03^{a b c}$ & $-0.48 \pm 0.11 c^{\mathrm{def}}$ \\
\hline $\mathrm{T} 4$ & $-0.12 \pm 0.19^{a b c}$ & $-0.23 \pm 0.41^{\mathrm{abcd}}$ & $-0.85 \pm 0.13^{f}$ \\
\hline $\mathrm{T} 5$ & $0.13 \pm 0.10^{\mathrm{a}}$ & $-0.61 \pm 0.15^{\mathrm{def}}$ & $-0.81 \pm 0.14^{\mathrm{ef}}$ \\
\hline \multicolumn{4}{|c|}{$b^{*}$} \\
\hline $\mathrm{T} 1$ & $0.82 \pm 0.28^{f}$ & $0.80 \pm 0.63^{f}$ & $0.93 \pm 0.35^{\mathrm{ef}}$ \\
\hline $\mathrm{T} 2$ & $1.66 \pm 1.01^{\text {cdef }}$ & $1.16 \pm 0.10^{\mathrm{f}}$ & $1.25 \pm 0.76^{\mathrm{def}}$ \\
\hline T3 & $5.51 \pm 0.33^{a}$ & $4.76 \pm 0.59^{\mathrm{ab}}$ & $4.25 \pm 0.22^{\mathrm{ab}}$ \\
\hline $\mathrm{T} 4$ & $4.16 \pm 1.64^{\mathrm{ab}}$ & $3.80 \pm 0.52 a^{b c}$ & $4.85 \pm 0.71^{\mathrm{ab}}$ \\
\hline $\mathrm{T} 5$ & $5.58 \pm 0.97^{a}$ & $3.83 \pm 0.12^{\mathrm{abc}}$ & $5.35 \pm 41^{\mathrm{ab}}$ \\
\hline
\end{tabular}

Data are given as mean values \pm standard deviation. Different letters within the same row indicate significant differences (Tukey's Test, $p<0.05$ ) between mean values.

For eggs coated with the SPS-based coating containing $6 \%$ TEO, $a^{*}$ values were significantly higher (reddish color) than uncoated eggs and other coated eggs after one and three weeks. However, there was no significant $(p>0.05)$ difference between uncoated and coated eggs after five weeks of storage in terms of $a^{*}$ values. There was a significant $(p<0.05)$ increase in yellowness $\left(b^{*}\right.$ values) for eggs that were coated with different concentrations of TEO compared to their counterparts that were uncoated or coated with SPS. These findings indicate that the incorporation of TEO significantly 
increases the yellowness of coated eggs. Issa et al. [7] reported the same trend for the SPS-based films with TEO. They concluded that by increasing the oil concentrations, the $b^{*}$ value of the film is also increased. This effect could be related to the light scattering impact of oil droplets in the film. The oil droplets in the film could enhance the lightness index of the film.

\subsection{Weight Loss}

Previous studies have shown that during storage time, the egg weight decreases significantly, since moisture and gases escape from the shell [23]. Figure 1 depicted the percentage of weight loss for coated and uncoated eggs. The results indicated that the eggs that were coated with either SPS alone or SPS incorporated with different concentrations of TEO exhibited significantly $(p<0.05)$ lower weight loss compared to their uncoated counterparts. The highest weight loss recorded was approximately $17 \%$ for uncoated eggs, and the lowest percentage was $3 \%$ for eggs coated with the SPS-based coating with TEO. The hydrophobic properties of TEO minimized the loss of water, in addition, SPS coats are an excellent seal for pores on the shell of the egg. Wardy et al. [21] indicated that coating with soybean oil reduced weight loss by at least 9.8 and 4.0 times for soybean oil-chitosan when compared with uncoated eggs after five weeks at $25^{\circ} \mathrm{C}$. There are many factors involved that could contribute to the different weight losses observed in both studies. These factors include the different coating materials used, egg size, shell porosity, relative humidity, hens' age, and the initial albumen quality of eggs expressed by the Haugh unit.

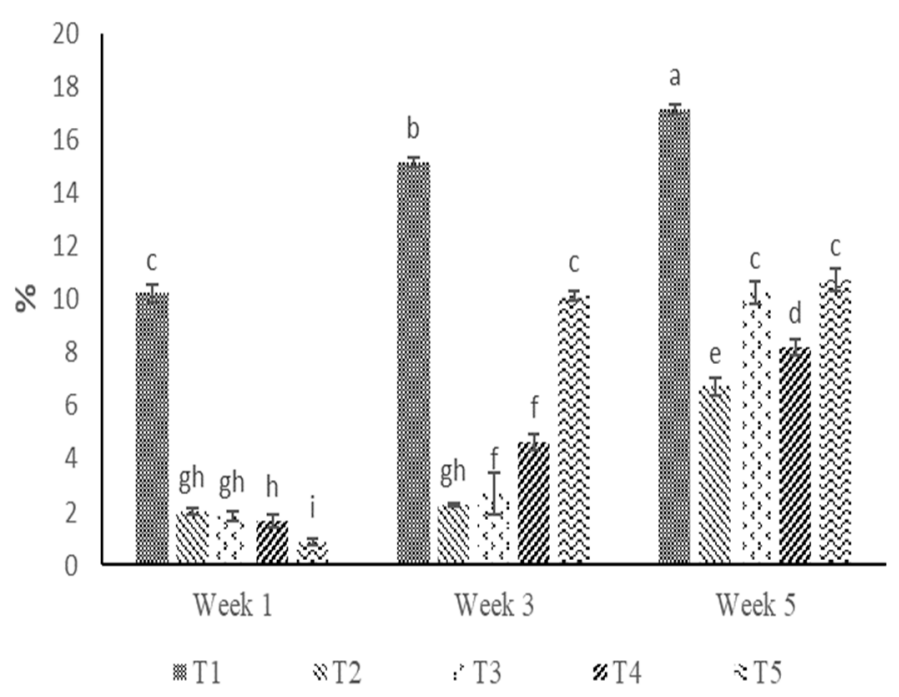

Figure 1. Weight loss of non-coated and coated eggs during five weeks of storage at $25^{\circ} \mathrm{C}$. Data are given as mean values \pm standard deviation. Small bars on the top of data bars indicate standard deviation. Different letters on the top of SD bars indicate significant differences (Tukey's Test, $p<0.05$ ) between mean values.

For edible coating of starches, according to Liu [24], the gas transfer occurs through the non-crystalline regions of the material (amorphous areas), and the advancement of the recrystallization process reduces the amorphous regions, offering less space for gas transfer. Suppakul et al. [25] concluded that table eggs which were coated with cellulose exhibited lower weight loss compared to their uncoated samples $(4.28 \%$ versus $8.33 \%, p<0.05)$. The findings of the present study confirmed the findings of Suppakul et al. [25]. A weight loss of $2 \%-3 \%$ is acceptable in the marketing of eggs according to Food and Agriculture Organization of the United Nation (FAO) [26]. In our study, the SPS-based coating with TEO was able to keep the weight loss close to the acceptable range after five weeks of storage at $25^{\circ} \mathrm{C}$. These results demonstrated that the SPS-based coating incorporated with TEO could be effective as a protective barrier against moisture transfer through the eggshell, which lowers the weight loss of eggs during storage time. 


\section{6. $p H$ Values}

Figure 2 represents the changes in the $\mathrm{pH}$ of the albumen of coated and uncoated eggs that were stored at $25{ }^{\circ} \mathrm{C}$ for five weeks. Egg freshness and quality can be estimated from the albumen $\mathrm{pH}$. The albumen $\mathrm{pH}$ of freshly laid eggs ranges between 7.6 and 8.5 [27]. In the present study, the $\mathrm{pH}$ value for uncoated eggs significantly $(p<0.05)$ increased after five weeks of storage. After the egg is laid, $\mathrm{CO}_{2}$ loss through eggshell pores occurs. This leads to changes in the bicarbonate buffer system. As a result, the albumen $\mathrm{pH}$ increases during storage [28]. The lowest $\mathrm{pH}$ values were recorded for the eggs coated with only SPS-based coating. On the other hand, the continuing breakdown of the constituents in egg white and/or a change in the bicarbonate buffer system may lead to the decrease in albumen $\mathrm{pH}$ during storage [29]. However, before and after storage, differences in egg size, initial egg quality, and storage conditions (temperature, humidity, and period) may affect the albumen $\mathrm{pH}$ [9].

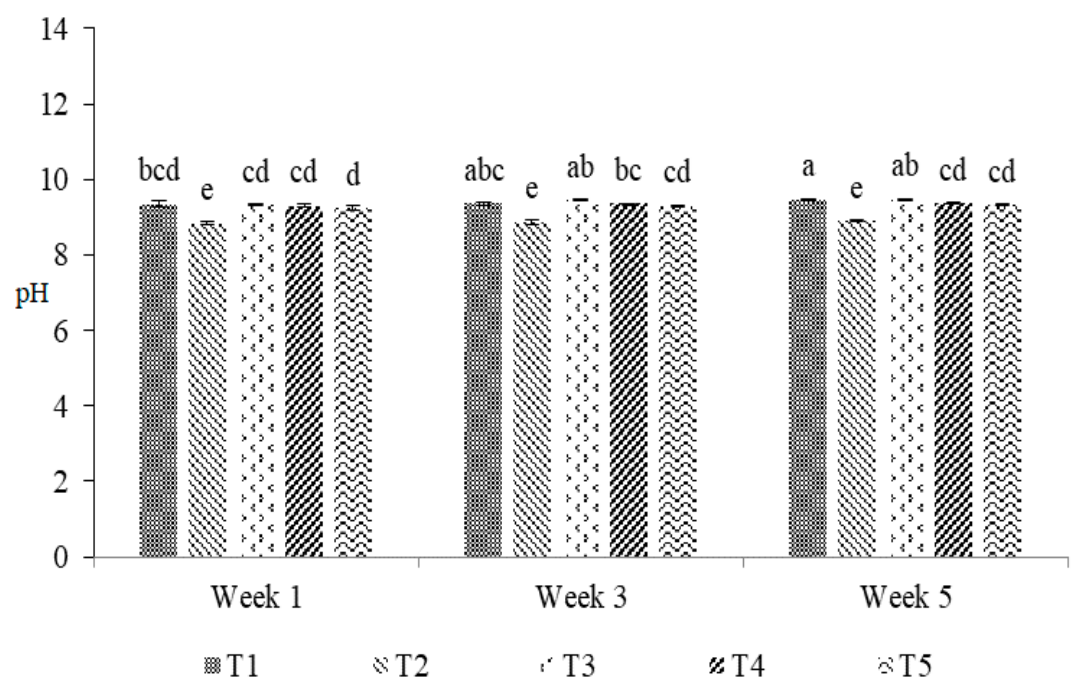

Figure 2. Albumen $\mathrm{pH}$ values of non-coated and coated eggs stored at $25^{\circ} \mathrm{C}$ for five weeks. Data are given as mean values \pm standard deviation. Small bars on the top of data bars indicate standard deviation. Different letters on the top of SD bars indicate significant differences (Tukey's Test, $p<0.05$ ) between mean values.

However, there was no significant $(p>0.05)$ difference in $\mathrm{pH}$ values for eggs that were coated with the SPS-based coatings containing $4 \%$ and $6 \%$ TEO. Apparently, SPS-based coating and SPS-based coating incorporated with TEO minimized $\mathrm{CO}_{2}$ loss throughout storage by acting as a gas barrier. Similar results were reported by Torrico, No, Prinyawiwatkul, Janes, Corredor, and Osorio [30]. They reported that there were no significant differences $(p>0.05)$ in the albumen $\mathrm{pH}$ among eggs coated with mineral oil or chitosan-mineral oil after five weeks of storage at $25^{\circ} \mathrm{C}$. The stable $\mathrm{pH}$ values were due to the excellent sealing of the SPS coat, in addition to the hydrophobic properties of TEOs, which was effective at minimizing the loss of carbon dioxide and water at the eggshell surface during long-term storage.

\subsection{Antibacterial Analysis}

Sadeyen et al. [31] highlighted that Salmonella is a common bacterium that is found in table eggs. Such pathogens inhabit the intestines of most avian species and are transmitted vertically in their offspring. The authors further highlighted that the risk of Salmonella infection increases with the time of storage. Table 5 shows the effects of five treatments on bacterial counts of Salmonella enterica (ATCC 53648) on the surface of eggs during storage at $25^{\circ} \mathrm{C}$. 
Table 5. Survival and growth of salmonella enterica on the surface of non-coated and coated eggs during five weeks of storage at $25^{\circ} \mathrm{C}$.

\begin{tabular}{cccccc}
\hline Week & T1 & T2 & T3 & T4 & T5 \\
\hline \multicolumn{5}{c}{$\log C F U / m L$} \\
\hline 1 & $6.67 \pm 0.41^{\mathrm{a}}$ & $5.61 \pm 0.02^{\mathrm{b}}$ & $5.52 \pm 0.05^{\mathrm{bc}}$ & $3.35 \pm 0.04^{\mathrm{e}}$ & $\mathrm{ND}^{\mathrm{f}}$ \\
\hline 5 & $4.78 \pm 0.34^{\mathrm{d}}$ & $4.03 \pm 0.02^{\mathrm{df}}$ & $4.79 \pm 0.03^{\mathrm{cd}}$ & $\mathrm{ND}^{\mathrm{f}}$ & $\mathrm{ND}^{\mathrm{f}}$ \\
\hline
\end{tabular}

Data are given as mean values \pm standard deviation. Different letters within the same row indicate significant differences (Tukey's Test, $p<0.05$ ) between mean values. Initial bacterial population was $7.95 \pm 0.75$. ND-Non-detectable (below detectable level $<10 \mathrm{CFU} / \mathrm{mL}$ ).

The initial population of Salmonella in inoculated eggs was about $6.67 \log$ CFU/g. The viable numbers of bacteria were reduced from 6.67 to 4.78 on uncoated eggs after five weeks of storage. This could be due to the depletion of nutrients on the egg shells and competition with other microorganisms. The SPS coating with different concentrations of TEO significantly $(p<0.05)$ reduced the growth of Salmonella throughout the storage. However, when eggs were coated with $6 \%$ TEO, Salmonella enterica populations remained below the detectable level $(<10 \mathrm{CFU} / \mathrm{mL})$ after five weeks, indicating that $6 \%$ TEO exhibited potent antibacterial activity compared to other concentrations of TEO $(p<0.05)$. There was no significant $(p>0.05)$ difference between the antibacterial activity of edible coatings that contained $4 \%$ TEO and those that were contained $6 \%$ TEO. Therefore, the optimum concentration of TEO that exhibited antibacterial activity against Salmonella enterica was 4\% TEO. The findings of the present study were similar to Alotaibi and Tahergorabi [8], who reported that TEO incorporated in SPS-based coating is effective in reducing the total plate count of bacteria on shrimp meat during storage time.

The antimicrobial activity of TEO is attributed to their essential oils, which contain terpenes thymol (5-methyl-2-[1-methylethyl) phenol]). Gram-negative bacteria are sensitive to thymol, since thymol breaks down the cellular membrane of the bacteria and releases the lipopolysaccharides. Therefore, it increases the permeability of the cytoplasmic membrane to adenosine tri-phosphate. Phenolic compounds (terpenoids) such as thymol and carvacrol are abundant in TEO. However, lower concentrations of terpenes such as p-cymene and $\gamma$-terpinene exist in TEO. The terpenoids are active against a broad spectrum of microorganisms. The antimicrobial action of phenolic compounds, such as thymol and carvacrol, is expected to cause structural and functional damages to the cytoplasmic membrane [5].

The present study also implicated that the bacteriostatic and bactericidal actions of TEO are dependent on its concentration. In fact, SPS-based coatings containing 6\% TEO exhibited higher bactericidal or bacteriostatic activity compared to $2 \%$ or $4 \%$ TEO. The findings in this study are in agreement with those of Issa et al. [5], who highlighted that 6\% TEO exhibited potent antibacterial activity against major food-borne microbes. The present study further showed that the synergistic antibacterial activity of SPS and TEO was evident with $4 \%$ and $6 \%$ TEO. Considering the economic loss resulting from the microbial contamination of food items, edible coatings based on SPS incorporated with TEO provide viable options for ensuring the safety of the eggs. Therefore, it could be desirable to apply the addition of TEO as an antimicrobial agent to SPS for the coating of eggs, to achieve the inhibition effect of Salmonella enterica.

\section{Conclusions}

The present study indicated that SPS-based coating incorporated with TEO can improve the safety of eggs, and maintain the quality of coated eggs (Haugh units, yolk index, shell breaking strength, shell color, albumen $\mathrm{pH}$, and weight loss) during the storage at $25^{\circ} \mathrm{C}$. In some countries around the world access to a refrigerator is difficult. Therefore, surface coating could be an alternative method to preserve the internal quality of eggs and prevent microbial contamination. This practice may help 
reduce economical loss from breakage as well as extend the shelf-life of eggs, which would ultimately save money for consumers and the food industry.

Author Contributions: Conceptualization, R.T. and A.S.; Methodology, A.S.; Software, A.S.; Validation, S.A. and R.T.; Formal Analysis, S.A.; Investigation, S.A.; Resources, R.T.; Data Curation, S.A.; Writing-Original Draft Preparation, S.A.; Writing-Review and Editing, R.T.; Visualization, S.A.; Supervision, R.T.; Project Administration, R.T.; Funding Acquisition, R.T.

Funding: This research was funded through the National Institute for Food and Agriculture of the United States Department of Agricultural, Project No. NC.X-311-5-18-170-1, in the Agricultural Research Program, North Carolina Agricultural and Technical State University.

Acknowledgments: The authors appreciate the support from Department of Family and Consumer Sciences at NC A\&T SU and the United States Department of Agriculture.

Conflicts of Interest: The authors declare no conflict of interest.

\section{References}

1. $\quad$ Bhale, S.; No, H.K.; Prinyawiwatkul, W.; Farr, A.J.; Nadarajah, K.; Meyers, S.P. Chitosan coating improves shelf life of eggs. J. Food Sci. 2003, 68, 2378-2383. [CrossRef]

2. Watson, R.R. (Ed.) Eggs and Health Promotion; John Wiley \& Sons: Hoboken, NJ, USA, 2008.

3. Van Immerseel, F.; Nys, Y.; Bain, M. (Eds.) Improving the Safety and Quality of Eggs and Egg Products: Egg Safety and Nutritional Quality; Elsevier: Amsterdam, The Netherlands, 2011.

4. Nazzaro, F.; Fratianni, F.; De Martino, L.; Coppola, R.; De Feo, V. Effect of essential oils on pathogenic bacteria. Pharmaceuticals 2013, 6, 1451-1474. [CrossRef] [PubMed]

5. Issa, A.; Ibrahim, S.A.; Tahergorabi, R. Impact of sweet potato starch-based nanocomposite films activated with thyme essential oil on the shelf-life of baby spinach leaves. Foods 2017, 6, 43. [CrossRef]

6. Jouki, M.; Yazdi, F.T.; Mortazavi, S.A.; Koocheki, A.; Khazaei, N. Effect of quince seed mucilage edible films incorporated with oregano or thyme essential oil on shelf life extension of refrigerated rainbow trout fillets. Int. J. Food Microbiol. 2014, 174, 88-97. [CrossRef] [PubMed]

7. Issa, A.T.; Schimmel, K.A.; Worku, M.; Shahbazi, A.; Ibrahim, S.A.; Tahergorabi, R. Sweet potato starch-based nanocomposites: Development, characterization, and biodegradability. Starch-Stärke 2018, 70, 1700273. [CrossRef]

8. Alotaibi, S.; Tahergorabi, R. Development of a sweet potato starch-based coating and its effect on quality attributes of shrimp during refrigerated storage. LWT-Food Sci. Technol. 2018, 88, 203-209. [CrossRef]

9. Silversides, F.G.; Budgell, K. The relationships among measures of egg albumen height, $\mathrm{pH}$, and whipping volume. Poult. Sci. 2004, 83, 1619-1623. [CrossRef] [PubMed]

10. Stadelman, W.J. Quality identification of shell eggs. In Egg Science and Technology; Stadelman, W.J., Cotterill, O.J., Eds.; Haworth Press Inc.: New York, NY, USA, 1995; pp. 39-66.

11. Caner, C.; Cansiz, Ö. Chitosan coating minimises eggshell breakage and improves egg quality. J. Sci. Food Agric. 2008, 88, 56-61. [CrossRef]

12. Jindal, V.K.; Sritham, E. Detecting eggshell cracks by acoustic impulse response and artificial neural networks. In 2003 ASAE Annual Meeting; American Society of Agricultural and Biological Engineers: Las Vegas, NV, USA, 27-30 July 2003; p. 1.

13. Karoui, R.; Kemps, B.; Bamelis, F.; De Ketelaere, B.; Decuypere, E.; De Baerdemaeker, J. Methods to evaluate egg freshness in research and industry: A review. Eur. Food Res. Technol. 2006, 222, 727-732. [CrossRef]

14. Mota, A.S.D.B.; Abreu, V.K.G.; Pereira, A.L.F.; Freitas, E.R.D.; Silva, D.S.; Lima, P.M.D.S. Internal quality of eggs coated with cassava and yam starches. Revista Brasileira de Ciências Agrárias 2017, 12, 47-50. [CrossRef]

15. Yüceer, M.; Caner, C. Antimicrobial lysozyme-chitosan coatings affect functional properties and shelf life of chicken eggs during storage. J. Sci. Food Agric. 2014, 94, 153-162. [CrossRef] [PubMed]

16. Caner, C. Whey protein isolate coating and concentration effects on egg shelf life. J. Sci. Food Agric. 2005, 85, 2143-2148. [CrossRef]

17. Obanu, Z.A.; Mpieri, A.A. Efficiency of dietary vegetable oils in preserving the quality of shell eggs under ambient tropical conditions. J. Sci. Food Agric. 1984, 35, 1311-1317. [CrossRef] 
18. Pujols, K.D.; Osorio, L.; Carrillo, E.P.; Wardy, W.; Torrico, D.D.; No, H.K.; Corredor, J.A.; Prinyawiwatkul, W. Comparing effects of $\alpha$-vs. $\beta$-chitosan coating and emulsion coatings on egg quality during room temperature storage. Int. J. Food Sci. Technol. 2014, 49, 1383-1390. [CrossRef]

19. Mertens, K.; Bamelis, F.; Kemps, B.; Kamers, B.; Verhoelst, E.; De Ketelaere, B.; Bain, M.; Decuypere, E.; De Baerdemaeker, J. Monitoring of eggshell breakage and eggshell strength in different production chains of consumption eggs. Poult. Sci. 2006, 85, 1670-1677. [CrossRef] [PubMed]

20. Zhao, Y.; Wang, J.; Lu, Q.; Jiang, R. Pattern recognition of eggshell crack using PCA and LDA. Innov. Food Sci. Emerg. Technol. 2010, 11, 520-525. [CrossRef]

21. Wardy, W.; Torrico, D.D.; Jirangrat, W.; No, H.K.; Saalia, F.K.; Prinyawiwatkul, W. Chitosan-soybean oil emulsion coating affects physico-functional and sensory quality of eggs during storage. LWT-Food Sci. Technol. 2011, 44, 2349-2355. [CrossRef]

22. Odabaşi, A.Z.; Miles, R.D.; Balaban, M.O.; Portier, K.M. Changes in brown eggshell color as the hen ages. Poult. Sci. 2007, 86, 356-363.

23. Wardy, W.; Torrico, D.D.; Herrera Corredor, J.A.; No, H.K.; Zhang, X.; Xu, Z.; Prinyawiwatkul, W. Soybean oil-chitosan emulsion affects internal quality and shelf-life of eggs stored at 25 and $4{ }^{\circ} \mathrm{C}$. Int. J. Food Sci. Technol. 2013, 48, 1148-1156. [CrossRef]

24. Liu, Z. Edible films and coatings from starches. In Innovations in Food Packaging; Han, J.H., Ed.; Academic Press: Oxford, UK, 2005; pp. 318-332.

25. Suppakul, P.; Jutakorn, K.; Bangchokedee, Y. Efficacy of cellulose-based coating on enhancing the shelf life of fresh eggs. J. Food Eng. 2010, 98, 207-213. [CrossRef]

26. FAO. Egg marketing-a guide for the production and sale of eggs. FAO Agric. Serv. Bull. 2003, 150, $29-51$.

27. Waimaleongora-Ek, P.; Garcia, K.M.; No, H.K.; Prinyawiwatkul, W.; Ingram, D.R. Selected quality and shelf life of eggs coated with mineral oil with different viscosities. J. Food Sci. 2009, 74, S423-S429. [CrossRef] [PubMed]

28. Keener, K.M.; LaCrosse, J.D.; Babson, J.K. Chemical Method for Determination of Carbon Dioxide Content in Egg Yolk and Egg Albumen 12. Poult. Sci. 2001, 80, 983-987. [CrossRef] [PubMed]

29. Biladeau, A.M.; Keener, K.M. The effects of edible coatings on chicken egg quality under refrigerated storage. Poult. Sci. 2009, 88, 1266-1274. [CrossRef]

30. Torrico, D.D.; No, H.K.; Prinyawiwatkul, W.; Janes, M.; Corredor, J.A.; Osorio, L.F. Mineral oil-chitosan emulsion coatings affect quality and shelf-life of coated eggs during refrigerated and room temperature storage. J. Food Sci. 2011, 76, S262-S268. [CrossRef] [PubMed]

31. Sadeyen, J.R.; Trotereau, J.; Protais, J.; Beaumont, C.; Sellier, N.; Salvat, G.; Velge, P.; Lalmanach, A.C. Salmonella carrier-state in hens: Study of host resistance by a gene expression approach. Microbes Infect. 2006, 8, 1308-1314. [CrossRef]

(c) 2019 by the authors. Licensee MDPI, Basel, Switzerland. This article is an open access article distributed under the terms and conditions of the Creative Commons Attribution (CC BY) license (http://creativecommons.org/licenses/by/4.0/). 